Supplement of Biogeosciences, 15, 4627-4645, 2018

https://doi.org/10.5194/bg-15-4627-2018-supplement

(C) Author(s) 2018. This work is distributed under

the Creative Commons Attribution 4.0 License.

(c) (1)

Supplement of

\title{
An evaluation of SMOS L-band vegetation optical depth (L-VOD) data sets: high sensitivity of L-VOD to above-ground biomass in Africa
}

Nemesio J. Rodríguez-Fernández et al.

Correspondence to: Nemesio J. Rodríguez-Fernández (nemesio.rodriguez@ cesbio.cnes.fr)

The copyright of individual parts of the supplement might differ from the CC BY 4.0 License. 


\section{Correlation computation}

To get a quantitative assessment of the correlation and the dispersion of L-VOD versus the evaluation datasets, three correlation coefficients were computed. First, the Pearson correlation coefficient $R$ of two variables $x_{1}, \ldots x_{n}$ and $y_{1} \ldots y_{n}$ was computed as:

$R=\frac{\sum_{i=1}^{n}\left(x_{i}-\bar{x}\right)\left(y_{i}-\bar{y}\right)}{\sqrt{\sum_{i=1}^{n}\left(x_{i}-\bar{x}\right)^{2}} \sqrt{\sum_{i=1}^{n}\left(y_{i}-\bar{y}\right)^{2}}}$

where, $\bar{x}$ and $\bar{y}$ are the means of each variable. $R$ is a measure of the linear correlation between two variables. If the relationship linking these variables is linear with no dispersion, $R$ equals 1 (both variables increase together) or -1 (one variable 5 increases when the other decreases).

However, the relationships between L-VOD and the evaluation data are not expected to be linear in most of the cases. Therefore, two rank correlations were also computed to quantify monotonic relationships whether linear or not. The Spearman's correlation coefficient $\rho$ is the Pearson correlation coefficient $R$ computed on the rank of the two variables instead of the variables themselves. If there are no repeated data values, a perfect Spearman correlation of $+1 /-1$ occurs when each of the variables is a perfect monotonic function of the other. In addition, Kendall's rank correlation was also computed. Kendall's correlation coefficient $\tau$ is given by:

$\tau=\frac{n_{\text {concordant }}-n_{\text {discordant }}}{n(n-1) / 2}$

where $n_{\text {concordant }}$ and $n_{\text {discordant }}$ are the number of concordant and discordant pairs, respectively. Given a pair of observations $\left(x_{i}, y_{i}\right)$ and $\left(x_{j}, y_{j}\right)$, they are said to be concordant if $y_{j}>y_{i}$ for $x_{j}>x_{i}$ or $y_{j}<y_{i}$ for $x_{j}<x_{i}$. Otherwise, the pair is said to be discordant. The denominator is the total number of pair combinations, so $\tau$ is in the range $[-1,1]$. 

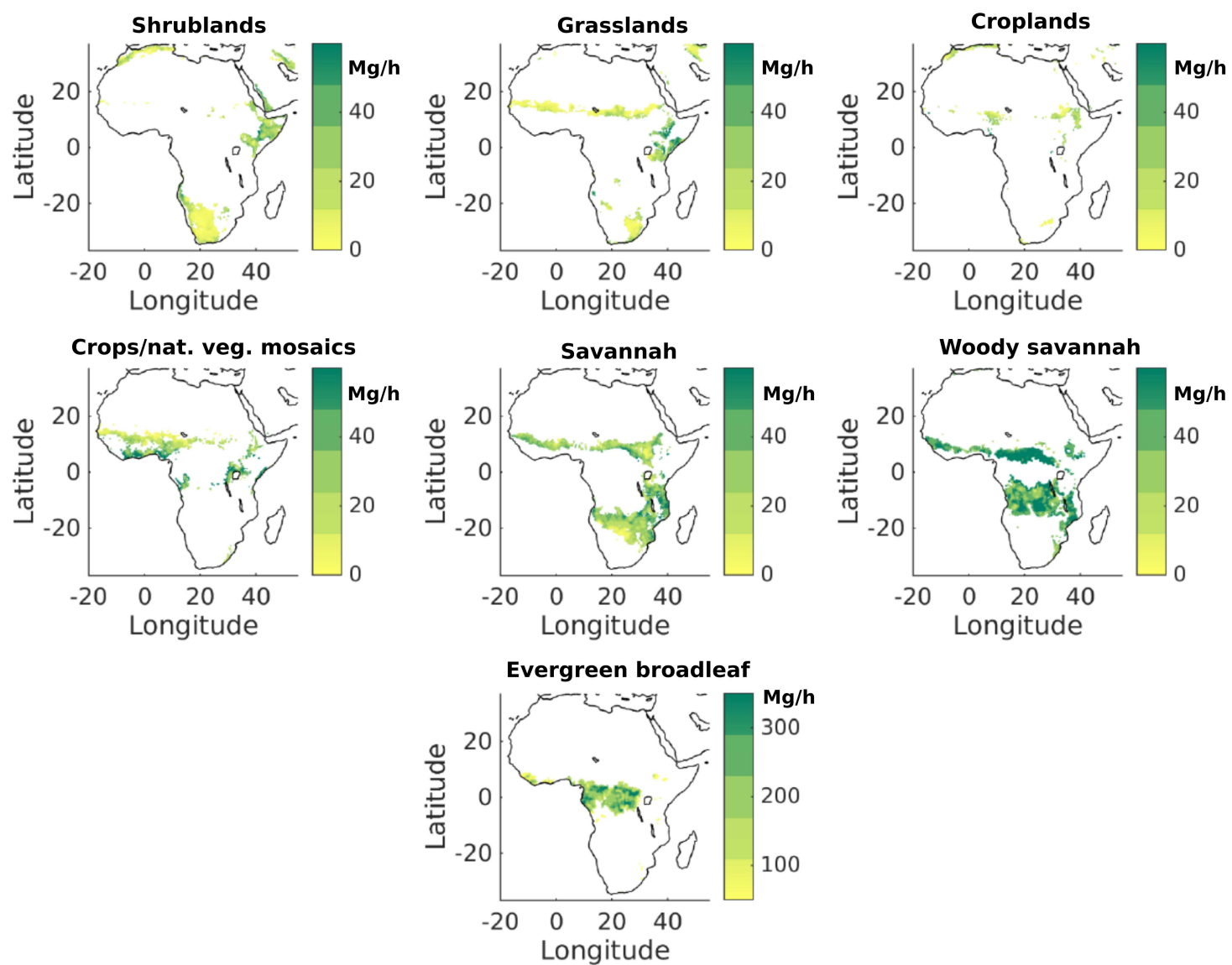

Figure S1. Spatial distribution of the IGBP land cover classes used in this study (Table S2) shown in the Bouvet-Mermoz AGB map. 

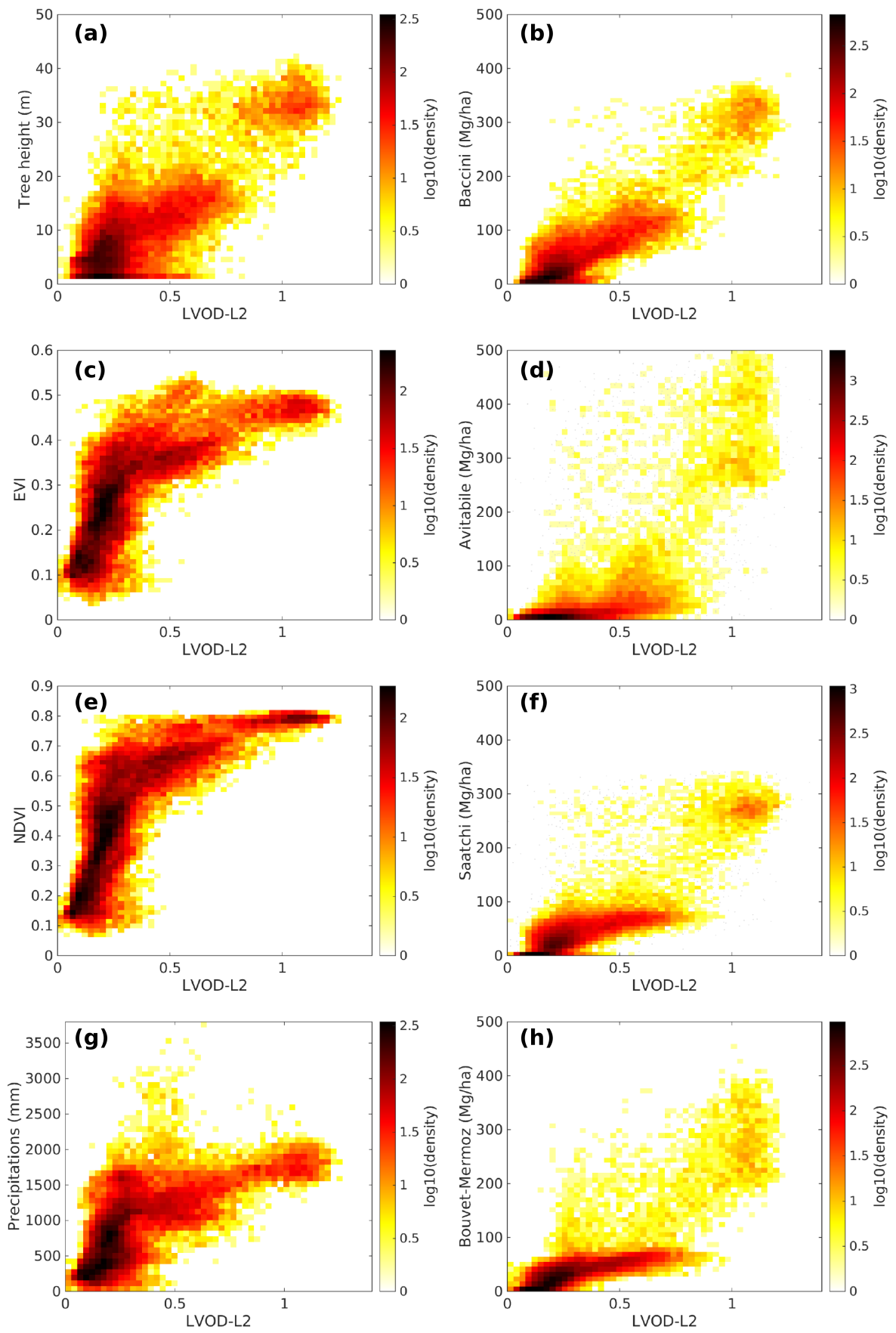

Figure S2. Density scatter plots of the 2011 annual mean of SMOS iL2 L-VOD respect to (from top to bottom and from left to right): tree height, EVI, NDVI, cumulated precipitation, Baccini et al. (2012), Avitabile et al. (2016), Saatchi et al. (2011) and Bouvet-Mermoz AGB datasets. 

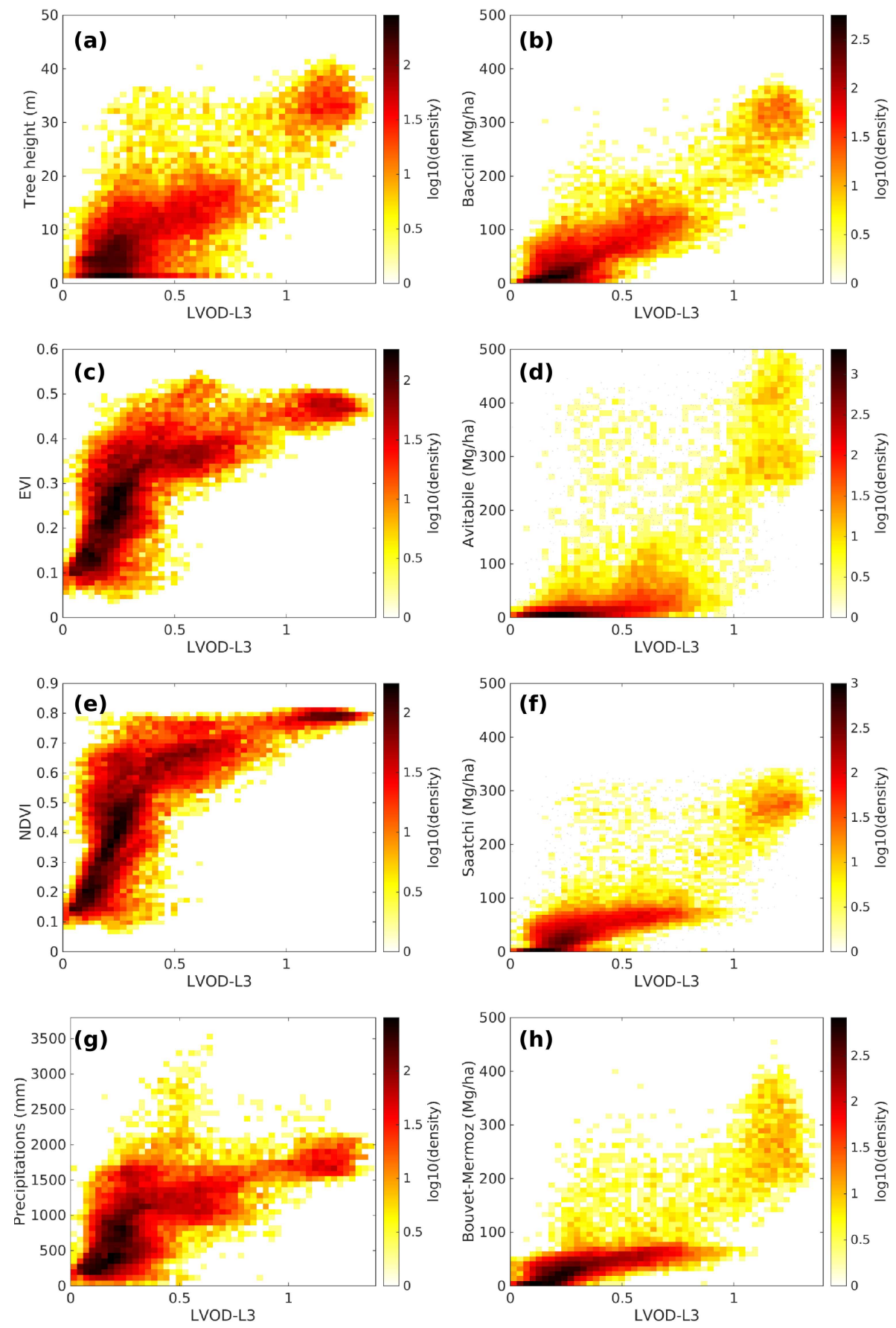

Figure S3. Density scatter plots of the 2011 annual mean of SMOS L3 L-VOD respect to (from top to bottom and from left to right): tree height, EVI, NDVI, cumulated precipitation, Baccini et al. (2012), Avitabile et al. (2016), Saatchi et al. (2011) and Bouvet-Mermoz AGB datasets. 
Table S1. Main characteristics of the three SMOS L-VOD products used in this study.

\begin{tabular}{|c|c|c|c|}
\hline & ESA Level 2 & CATDS Level 3 & INRA-CESBIO \\
\hline Reference & Kerr et al. (2012) & Al Bitar et al. (2017) & Fernandez-Moran et al. (2017) \\
\hline Version used & 620 & 300 & 100 \\
\hline Soil texture & Ecoclimap & Ecoclimap & Ecoclimap \\
\hline Land cover & Ecoclimap & Ecoclimap & IGBP \\
\hline Soil temperature & ECMWF & ECMWF & ECMWF \\
\hline Forward model & L-MEB (Wigneron et al., 2007) & L-MEB (Wigneron et al., 2007) & L-MEB (Wigneron et al., 2007) \\
\hline \multirow{3}{*}{$\begin{array}{l}\text { Single-scattering } \\
\text { albedo }\end{array}$} & Low vegetation: 0 & Low vegetation:0 & Parrens et al. $(2017 b, a)$ \\
\hline & Tropical and subtropical forest: 0.06 & Tropical and subtropical forest: 0.06 & \\
\hline & Boreal forest: 0.08 & Boreal forest: 0.08 & \\
\hline \multirow[t]{2}{*}{ Roughness } & Low vegetation: 0.1 & Low vegetation: 0.1 & Parrens et al. $(2017 b, a)$ \\
\hline & Forest: 0.3 & Forest: 0.3 & \\
\hline \multirow[t]{2}{*}{ Multi-orbit } & no & yes, three orbits, L-VOD & no \\
\hline & & assumed to be correlated & \\
\hline \multirow[t]{3}{*}{ L-VOD first guess } & Computed from & Computed from & First inversion using a constant \\
\hline & Ecoclimap LAI & Ecoclimap LAI & value of 0.5 and second inversion using \\
\hline & & & a local average of the first retrievals \\
\hline SM first guess & ECMWF & ECMWF & $0.2 \mathrm{~m}^{3} / \mathrm{m}^{-3}$ \\
\hline Footprints with & SM and L-VOD retrieval only & SM and L-VOD retrieval only & SM and L-VOD retrieval \\
\hline inhomogeneous & for major fraction. Contribution & for major fraction. Contribution & for the whole footprint \\
\hline \multirow[t]{2}{*}{ land cover } & from minor fraction using & from minor fraction using & assumed to be homogeneous \\
\hline & ECMWF SM and Ecoclimap LAI & ECMWF SM and Ecoclimap LAI & \\
\hline Grid & ISEA & EASEv2 & EASEv2 \\
\hline Sampling & $15 \mathrm{~km}$ & $25 \mathrm{~km}$ & $25 \mathrm{~km}$ \\
\hline
\end{tabular}


Table S2. Land cover classes of the International Geosphere-Biosphere Program (IGBP) dataset (Loveland et al., 2000) used in this study.

\begin{tabular}{|c|c|c|}
\hline Number & Name & Description \\
\hline 2 & Evergreen broadleaf & $\begin{array}{l}\text { Lands dominated by broadleaf woody vegetation with a percent cover }>60 \% \\
\text { and height exceeding } 2 \mathrm{~m} \text {. Almost all trees and shrubs remain green } \\
\text { year round. Canopy is never without green foliage. }\end{array}$ \\
\hline 7 & Open shrublands & $\begin{array}{l}\text { Lands with woody vegetation less than } 2 \mathrm{~m} \text { tall and with shrub canopy cover } \\
\text { between } 10 \% \text { and } 60 \% \text {. The shrub foliage can be either evergreen or deciduous. }\end{array}$ \\
\hline 8 & Woody savannah & $\begin{array}{l}\text { Lands with herbaceous and other understory systems, and with forest } \\
\text { canopy cover between } 30 \% \text { and } 60 \% \text {. The forest cover height exceeds } 2 \mathrm{~m} \text {. }\end{array}$ \\
\hline 9 & Savannah & $\begin{array}{l}\text { Lands with herbaceous and other understory systems, and with forest } \\
\text { canopy cover between } 10 \% \text { and } 30 \% \text {. The forest cover height exceeds } 2 \mathrm{~m} \text {. }\end{array}$ \\
\hline 10 & Grasslands & Lands with herbaceous types of cover. Tree and shrub cover is less than $10 \%$. \\
\hline 12 & Croplands & $\begin{array}{l}\text { Lands covered with temporary crops followed by harvest and a bare } \\
\text { soil period (e.g., single and multiple cropping systems). Note that perennial } \\
\text { woody crops will be classified as the appropriate forest or shrub land cover type. }\end{array}$ \\
\hline 14 & $\begin{array}{l}\text { Croplands and natural } \\
\text { vegetation mosaics }\end{array}$ & $\begin{array}{l}\text { Lands with a mosaic of croplands, forests, shrubland, and grasslands in } \\
\text { which no one component comprises more than } 60 \% \text { of the landscape. }\end{array}$ \\
\hline
\end{tabular}

Table S3. Parameters of the fits of the AGB vs IC L-VOD of relationship of Fig. 5 using a logistic function (Eq. 2).

\begin{tabular}{lllllll}
\hline AGB & line & $a[\mathrm{Mg} / \mathrm{h}]$ & $b[-]$ & $c[-]$ & $d[\mathrm{Mg} / \mathrm{h}]$ & $\mathrm{R}^{2}$ \\
\hline Avitabile & 05th & 264.367 & 13.115 & 0.846 & 4.351 & 0.998 \\
Avitabile & Mean & 369.890 & 8.921 & 0.732 & 5.158 & 0.999 \\
Avitabile & 95th & 463.091 & 9.466 & 0.583 & 2.135 & 0.990 \\
Saatchi & 05th & 345.590 & 4.458 & 0.926 & -4.387 & 0.993 \\
Saatchi & Mean & 280.159 & 6.680 & 0.689 & 14.794 & 0.993 \\
Saatchi & 95th & 289.762 & 9.857 & 0.548 & 33.859 & 0.993 \\
Baccini & 05th & 455.774 & 2.785 & 0.964 & -40.357 & 0.990 \\
Baccini & Mean & 422.744 & 3.400 & 0.729 & -29.252 & 0.999 \\
Baccini & 95th & 393.863 & 4.685 & 0.558 & -6.444 & 0.997 \\
Bouvet-Mermoz & 05th & 296.709 & 4.511 & 0.966 & 2.129 & 0.987 \\
Bouvet-Mermoz & Mean & 325.043 & 5.116 & 0.774 & 7.651 & 0.996 \\
Bouvet-Mermoz & 95th & 355.989 & 7.267 & 0.589 & 19.731 & 0.994 \\
\hline
\end{tabular}



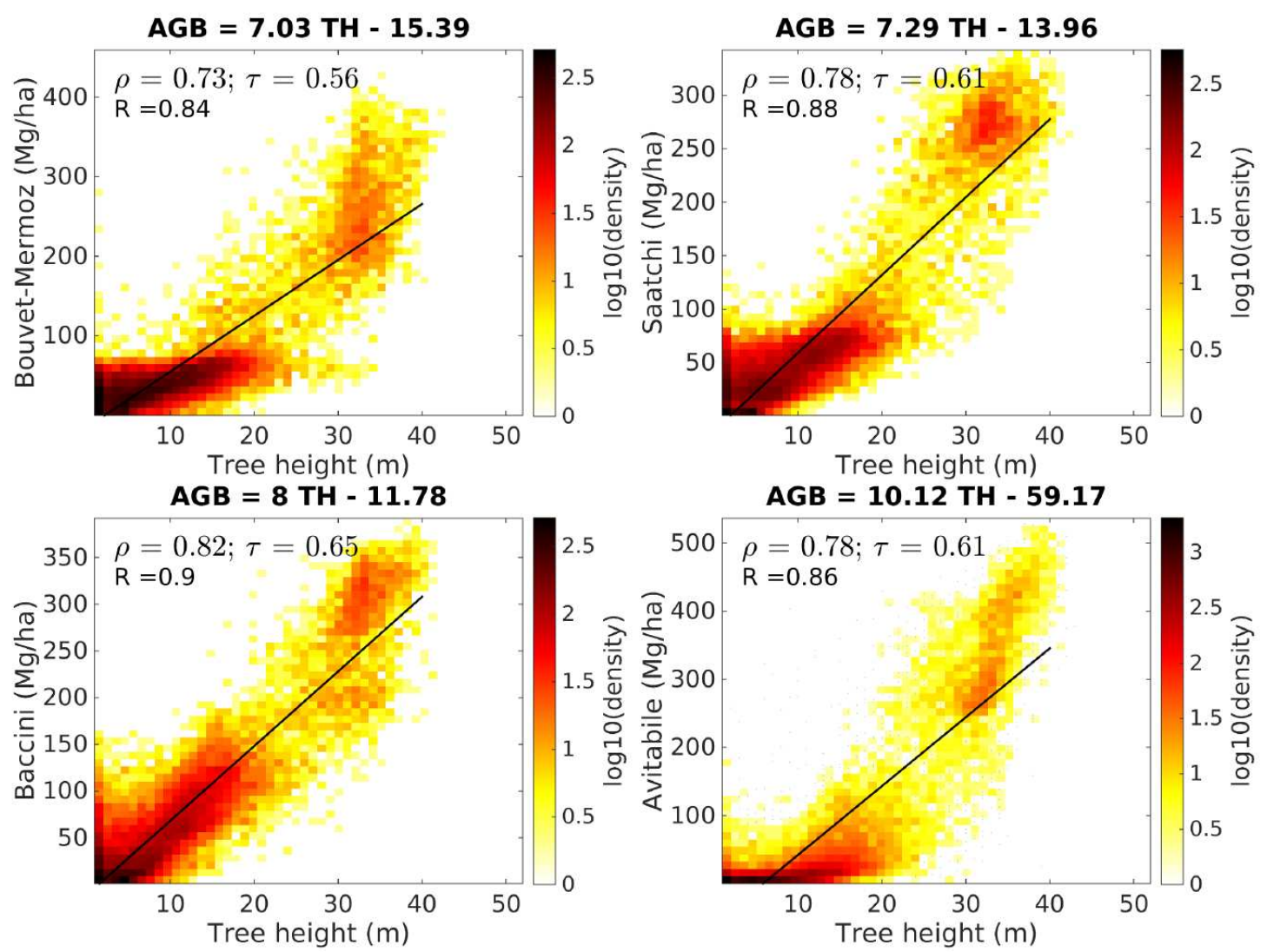

Figure S4. Scatter plots of the four AGB datasets as a function of Simard et al. (2011) tree height. 